\title{
Imaging the hydrothermal system beneath the Jigokudani valley, Tateyama volcano, Japan: implications for structures controlling repeated phreatic eruptions from an audio-frequency magnetotelluric survey
}

\author{
Kaori Seki ${ }^{*}$, Wataru Kanda ${ }^{2}$, Yasuo Ogawa ${ }^{2}$, Toshiya Tanbo ${ }^{3}$, Tomokazu Kobayashi ${ }^{4}$, Yuta Hino ${ }^{1,5}$ \\ and Hideaki Hase ${ }^{2,6}$
}

\begin{abstract}
This study focuses on the results of an audio-frequency magnetotelluric (AMT) survey across the Jigokudani valley, Tateyama volcano, Japan, to investigate the spatial relationship between the distribution of electrical resistivity and geothermal activity and to elucidate the geologic controls on both its phreatic eruption history and recent increase in phreatic activity. The AMT data were collected at eight locations across the Jigokudani valley in September 2013, with high quality data obtained from most sites, enabling the identification of an underground 2D resistivity structure from the transverse magnetic (TM) mode data. The data obtained during this study provided evidence of a large conductive region beneath the surface of the Jigokudani valley that is underlain by a resistive layer at depths below $500 \mathrm{~m}$. The resistive layer is cut by a relatively conductive region that extends subvertically toward the shallow conductor. The shallow conductive region is divided into an uppermost slightly conductive section that is thought to be a lacustrine sediment layer of an extinct crater lake containing hydrothermal fluids and a lower section containing a mix of volcanic gases and hydrothermal fluids. The low permeability of the clay zone means that the uppermost clayey sediments allow the accumulation of gases in the lower section of the conductive region, suggesting the existence of a cap structure. The deep resistive layer likely consists of units similar to the granitic rocks that are widely exposed throughout the Jigokudani valley. We suggest that the relatively conductive zone that separates these granitic rocks represents a high-temperature volcanic gas conduit, given that the most active fumarole in the Jigokudani valley lies directly along the trajectory of this path.
\end{abstract}

Keywords: Resistivity structure; AMT; Tateyama volcano; Phreatic eruption; Hydrothermal system; Clay cap

\section{Findings}

\section{Introduction}

Phreatic eruptions, or hydrothermal eruptions, occur through the intense heating of groundwater by a hightemperature material of the magma origin such as volcanic gases and may occur in any volcanic system (e.g., Barberi et al. 1992; Germanovich and Lowell 1995).

\footnotetext{
*Correspondence: seki.k.ad@m.titech.ac.jp

1 Department of Earth and Planetary Sciences, Tokyo Institute of Technology, 2-12-1 Ookayama, Meguro, Tokyo 152-8551, Japan

Full list of author information is available at the end of the article
}

Phreatic eruptions are intrinsically connected to the hydrothermal systems present within volcanic edifices, given that these eruptions often contain ash consisting of hydrothermally altered minerals (e.g., Ohba and Kitade 2005). In addition, volcanic hydrothermal systems are often associated with low permeable clayey layers that consist of hydrothermally altered minerals and commonly develop within the shallow levels of volcanic edifices (e.g., Wright et al. 1985; Pellerin et al. 1996). The accumulation of upwelling volcanic gas beneath this low permeable

\section{Springer}

(c) 2015 Seki et al: licensee Springer. This is an Open Access article distributed under the terms of the Creative Commons Attribution License (http://creativecommons.org/licenses/by/4.0), which permits unrestricted use, distribution, and reproduction in any medium, provided the original work is properly credited. 
layer can lead to an increase in temperature and pressure that can potentially cause hydrothermal eruptions. This low permeable clayey layer is conductive and can be imaged using magnetotelluric (MT) methods (e.g., Ussher et al. 2000; Aizawa et al. 2013). The fact that gases are not as conductive as fluids or clays means that these low permeable clayey caps are often underlain by slightly resistive regions. A number of volcanoes that have multiple recorded phreatic eruptions have been investigated by magnetotelluric surveys, including Kusatsu-Shirane volcano in Japan (Nurhasan et al. 2006) and Taal volcano in the Philippines (Yamaya et al. 2013). A significant number of these volcanoes are associated with near-surface conductive anomalies that have been interpreted to be low permeable clayey layers.

Tateyama volcano (also called Midagahara volcano) is a composite volcano located in the Hida Mountains (Figure 1). The most significant volcanic activity associated with this volcano occurred during the Late Pleistocene (after $0.22 \mathrm{Ma}$; Harayama et al. 2000). Volcanic edifices in this region are dominated by gneiss and granite units (Yamasaki et al. 1966). The Jigokudani valley is an active solfatara field located in the northeast end of the Midagahara Plateau and is dominated by generally welded pyroclastic flow deposits that were erupted at about 0.1 Ma. The Jigokudani valley formed as a result of repeated phreatic eruptions some 40,000 years ago, during the last stage of volcanic activity in this area (Yamasaki et al. 1966; Harayama et al. 2000). Figure 1 shows the geology of the Jigokudani valley region (simplified from Harayama et al. 2000). The explosion craters around the Jigokudani valley define a NW-SE trend, as shown by dotted lines in Figure 1, which show the traces of these craters. Although the volcano has not erupted in historical times, four individual phreatic eruptions over the past 10,000 years have been identified from air-fall tephras (Kobayashi 1980). Nakano and Itoh (1998) investigated the historic documents and inferred that a phreatic eruption occurred in the Jigokudani valley in 1836 but was too small to produce tephra deposits. In addition, the location of the magma reservoir associated with the Tateyama volcano has been seismically inferred to be a few kilometers southeast of the Jigokudani valley at a depth of 2 to $4 \mathrm{~km}$ (Matsubara et al. 2000). A low resistivity area was also detected by

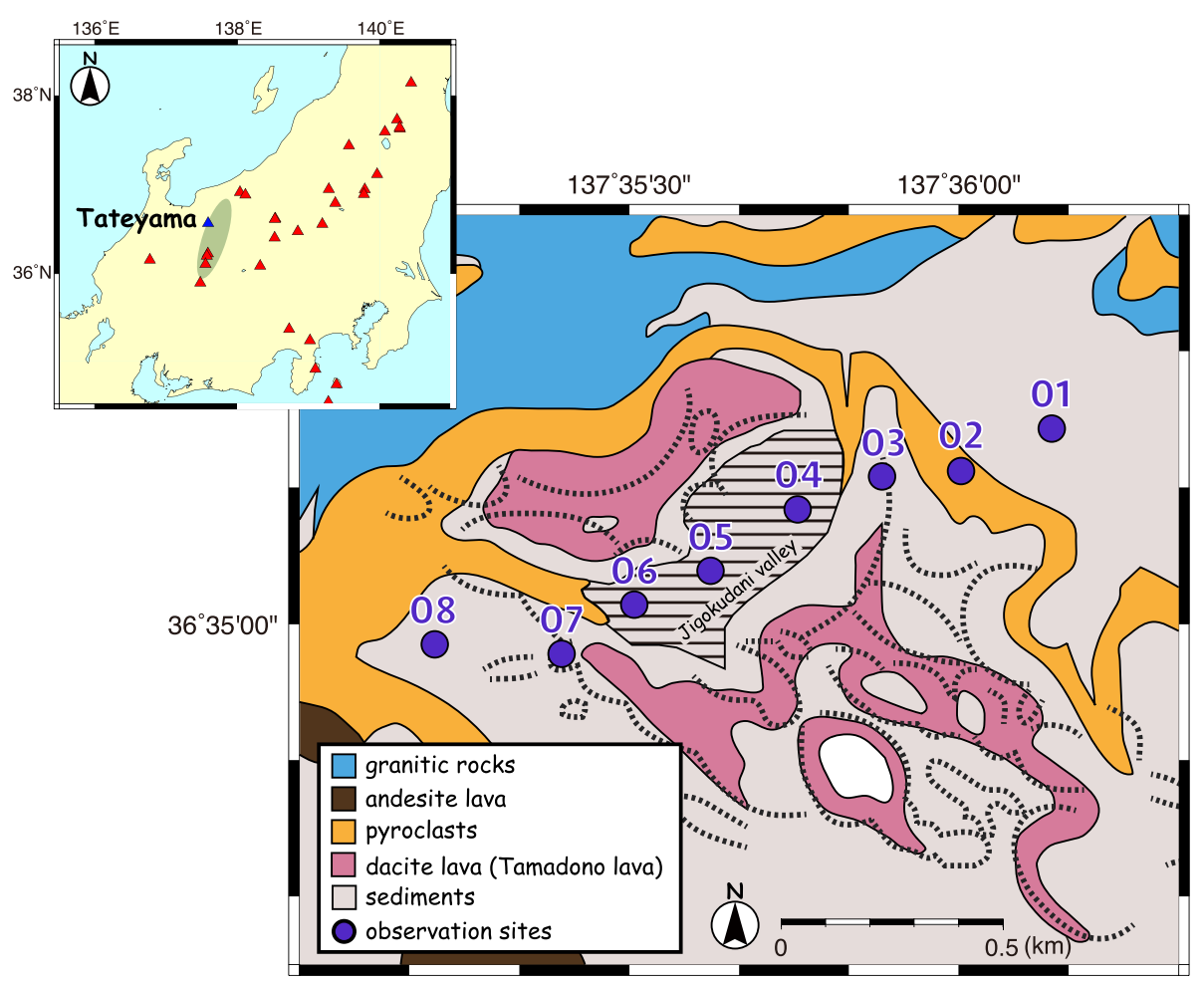

Figure 1 A simplified geological map of the area around the Jigokudani valley, adapted from Harayama et al. (2000). The hatched area represents the Jigokudani valley, and the dotted lines indicate the traces of hydrothermal eruption craters, some of which are connected one another by repeated eruptions and have ill-defined borders. The magmatic eruptions that formed lavas and pyroclastic flow deposits in this area occurred in the southeast of this map. Inset: Map showing central Japan, with red triangles indicating the location of active volcanoes, a gray shaded ellipse representing the location of the Hida Mountains, and a dark blue triangle showing the location of the Tateyama volcano in the northern part of the Hida Mountains. 
data acquired from a wide-band magnetotelluric survey at depths corresponding to this seismic anomaly (Ogawa et al. 2002).

Several recent anomalous events have been repeatedly observed in the study area, including a sulfur outflow in 2010 (Japan Meteorological Agency 2013a) and fumaroles with temperatures that exceed the boiling point of water, reaching a maximum of about $140^{\circ} \mathrm{C}$ (Japan Meteorological Agency 2013b). These fumarole vent gases have high $\mathrm{HCl} / \mathrm{SO}_{2}$ ratios, indicating that these gases were derived from high-temperature sources (Tokyo Institute of Technology et al. 2013). These events thus provide evidence of an increase in volcanic activity. However, only a few geophysical studies have been conducted in the Jigokudani valley to date, meaning that there is currently little information available on the shallow subsurface structure of this area. Here, we present the results of an audio-frequency magnetotelluric (AMT) survey within the Jigokudani valley, an area that has experienced multiple phreatic eruption events. These data provide information on the distribution of hydrothermal fluids and vapor reservoirs in this area and provide new constraints on the spatial relationship between subsurface structures and fumarolic activity, including the presence of cap structures that can store upwelling volcanic gases.

\section{Data}

We carried out an AMT survey across the Jigokudani valley in September 2013. This method uses magnetotelluric responses derived from variations in the natural audio-frequency band (approximately 1 to $10^{4} \mathrm{~Hz}$ ) of the electromagnetic field to estimate the resistivity structure in an area down to a depth of a few kilometers. The AMT data were collected at eight locations at approximately 200-m intervals along an ENE-WSW survey line crossing the Jigokudani valley (Figure 1). Two components of the electric field and three components of the magnetic field were recorded for 10 to $12 \mathrm{~h}$ overnight using a Phoenix Geophysics MTU-5A system (Phoenix Geophysics Ltd., Toronto, ON, Canada), barring site 07 , where electromagnetic fields were only measured for $3 \mathrm{~h}$ during the daytime. The AMT responses were estimated using mutual local references to reduce the influence of noise within the data, except for site 07 , where single-site processing was used due to the lack of available reference sites. The main noise sources are a trolley bus operated using a DC current that departs from the underground Murodo terminal (at the southern edge of Figure 1), and commercial $60 \mathrm{~Hz}$ frequency power supplied to lodges in this area. AC power is also supplied to the Jigokudani valley to monitor volcanic gases in this area.

Apparent resistivity and phase sounding curves for all the sites used during this study are shown in
Figure 2. High-quality data were obtained at most sites for frequencies higher than $10 \mathrm{~Hz}$, although the lower frequency data obtained at several sites have a tendency to have $\mathrm{XY}$ phase components that increase rapidly as frequencies decrease (e.g., sites 01 and 08), providing evidence of the 3D nature of the underground structure and/or the presence of local noise effects that cause breaks in plane wave approximations. The dead band (about 1,000 to $3,000 \mathrm{~Hz}$ ) sometimes contains low quality data, primarily as a result of the weakness of the natural-source signal, a factor that in turn influences the quality of the data obtained, particularly at site 03 . The apparent resistivity at sites 04 to 06 is further impaired by the $60-\mathrm{Hz}$ power supply in this area, although the apparent resistivity at sites in the Jigokudani valley (sites 04 to 06) is relatively low.

\section{D analysis}

\section{Dimensionality of structures in the study area}

Phase tensor analysis (Caldwell et al. 2004) was applied to the entirety of the dataset obtained during this study to determine the subsurface resistivity structure within the study area. The phase-tensor skew angle $(\beta)$ represents a measure of the dimensionality of a structure and is zero for $1 \mathrm{D}$ or $2 \mathrm{D}$ structures but increases in value as data are influenced by the presence of 3D structures (Caldwell et al. 2004). Figure 3 shows color-filled phase-tensor ellipses that indicate the skew angle for three representative frequencies. The majority of the skew angle magnitudes for all of these sites are less than $5^{\circ}$, with the exception of data obtained at low frequencies $(<10 \mathrm{~Hz})$, indicating that the Jigokudani valley has a $2 \mathrm{D}$ subsurface structure that is identifiable from the AMT data.

The 2D nature of the structures in the study area is also constrained by the shapes of phase-tensor ellipses and induction arrows (Figure 3). The major axes of the phase-tensor ellipses obtained at $9.4 \mathrm{~Hz}$ are roughly parallel to the survey line, and the ratios of major to minor axes lengths are generally large (Figure 3a). In contrast, these ellipses become more circular at higher frequencies (see $1,100 \mathrm{~Hz}$ in Figure 3c). In addition, real induction arrows (Parkinson 1962; Figure 3), which intrinsically tend to point toward lower resistivity areas, do not appear to have any preferential orientation or length at high frequencies $(1,100 \mathrm{~Hz}$; Figure 3c). In comparison, the arrows obtained for lower frequency data $(97 \mathrm{~Hz}$ and $9.4 \mathrm{~Hz}$; Figure 3a,b) point toward the central part of the study area. This suggests that the resistivity structure has lateral variations parallel to the survey line at depths corresponding to the low frequency data obtained during this study.

\section{Strike estimation}

The above discussion suggests that the study area has a $2 \mathrm{D}$ resistivity structure, and we have estimated the 

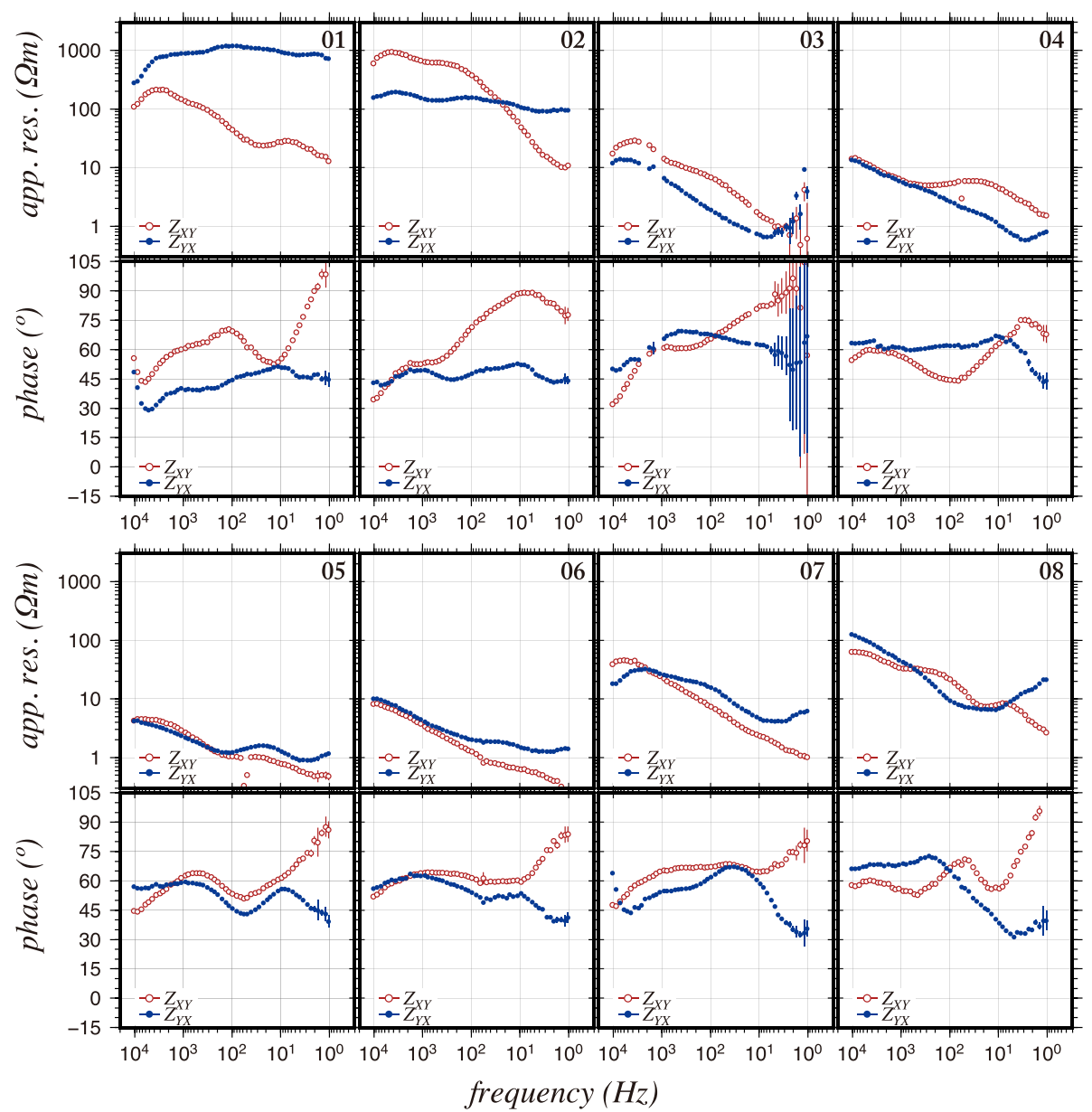

Figure 2 Apparent resistivity and impedance phase. Apparent resistivity (upper panel: app. res.) and impedance phase (lower panel: phase) observed at all the sites in the study area. Impedance tensor ( $Z_{X Y}$ and $\left.Z_{Y X}\right)$ off-diagonal components are shown in red and blue, respectively.

strike direction of this $2 \mathrm{D}$ structure using phase-tensor parameters. One of the principal axis directions of the phase-tensor ellipse coincides with the 2D strike in ideal 2D cases (Caldwell et al. 2004). Figure 4 shows polar histograms of the principal axis directions for three frequency bands obtained during this study; the lower frequency band ( 1 to $100 \mathrm{~Hz}$; Figure $4 \mathrm{~b}$ ) is dominated by $\mathrm{N} 30^{\circ} \mathrm{W}$ and $\mathrm{N} 60^{\circ} \mathrm{E}$ directions, whereas the higher frequency band has $\mathrm{N}$ and $\mathrm{E}$ dominated directions (100 to $10,000 \mathrm{~Hz}$; Figure 4c). A histogram for data from all frequency bands ( 1 to $10,000 \mathrm{~Hz}$; Figure $4 \mathrm{a}$ ) also indicates a similar directional property to that seen in Figure $4 \mathrm{~b}$. However, this analysis is inherently ambiguous by $90^{\circ}$, meaning that the geology of this area (Figure 1) and the distribution of induction arrows (Figure 3) must also be considered. A simplified geological map for the study area shows that the Tamadono lavas have a preferential SE to NW orientation and cross-cut the Jigokudani valley (Figure 1), with a similar tendency present in the distribution of pyroclastic flow deposits below these lavas. In addition, as stated above, the low frequency induction arrows are focused toward a central area along an orientation that nearly parallels the survey line. This evidence strongly suggests that the $2 \mathrm{D}$ structure in this area has a $2 \mathrm{D}$ strike of $\mathrm{N} 30^{\circ} \mathrm{W}$.

\section{D modeling}

The impedance tensor was rotated into the assumed strike direction $\left(\mathrm{N} 30^{\circ} \mathrm{W}\right)$ before being decomposed into transverse magnetic (TM) and transverse electric (TE) modes. Observation sites were projected onto a $560^{\circ} \mathrm{W}-\mathrm{N} 60^{\circ} \mathrm{E}$ line, orthogonal to the strike of the structure in this area. The data with large phase-tensor skew angles are inconsistent with the 2D structure assumed for the area; therefore, only the data with small skew angles data $\left(<5^{\circ}\right)$ were used in the $2 \mathrm{D}$ inversion undertaken during this study. This $2 \mathrm{D}$ inversion model was constructed using the inversion code developed by Ogawa and Uchida (1996), using TM-mode data with a 3\% error floor and did not include any topographical influence. The best-fit model shown in Figure 5 


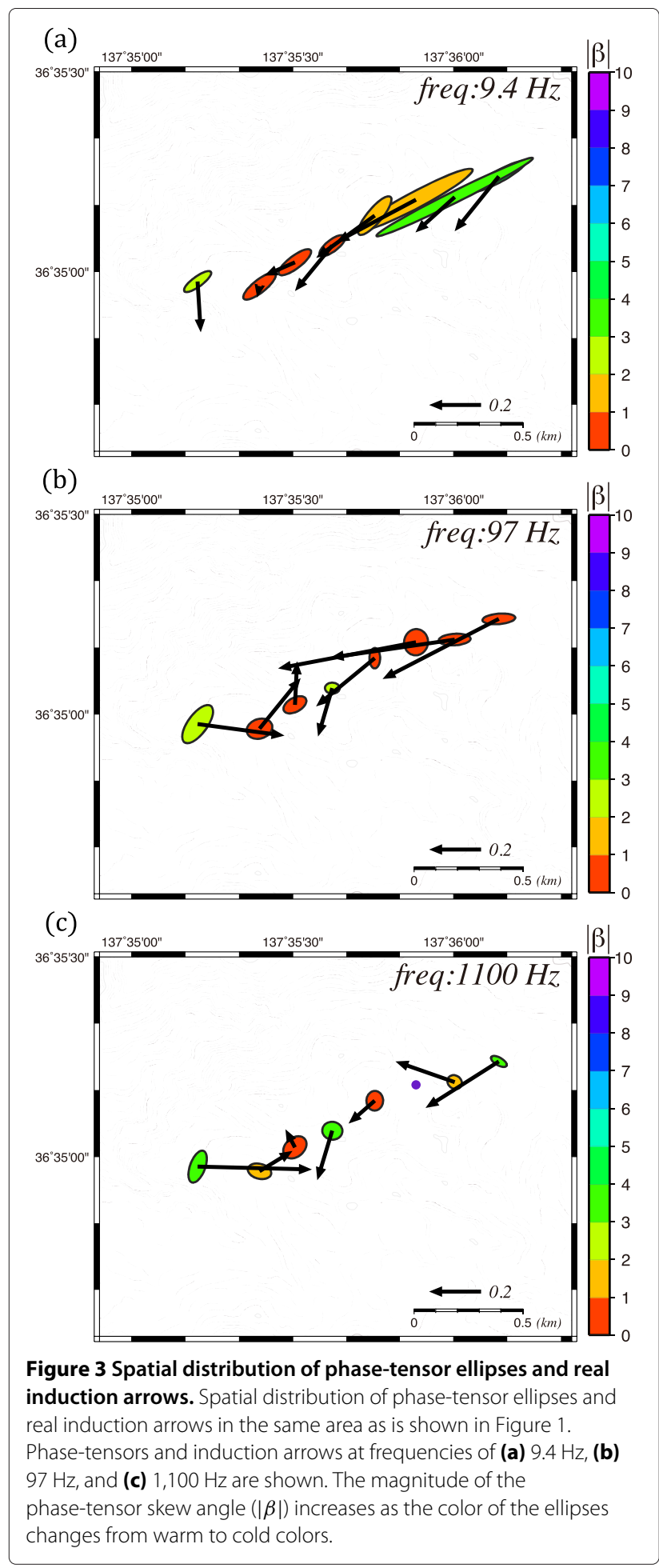

has a root mean square (RMS) misfit of 0.85 . Pseudosections for the measured and calculated responses are compared in Figure 6, with both figures agreeing well, except in areas without data.
Three characteristic features are present in the final model (Figure 5); a conductive body (less than $10 \Omega \mathrm{m}$ ) beneath the Jigokudani valley (between sites 04 and 06) that seems to be divided into a more conductive upper part ( $\mathrm{C} 1$ in Figure 5) and a less conductive lower part (C2), a resistive layer that has resistivity values of several hundreds of ohm meters at depths greater than $500 \mathrm{~m}$ (R1) with a similar resistive zone at shallower depths in the northeast of the study area (R2), and a relatively conductive zone (C3) that seems to separate the two resistive zones (R1 and R2) and extends subvertically from these portions to the shallow conductive body. These features are also present within the pseudo-sections for the study area (Figure 6). The shallow conductive region around the Jigokudani valley corresponds to the low apparent resistivity zone that extends from an area with high frequencies to an area with lower frequencies around the middle sites within the pseudo-section. The deep resistive layer is indicated by lower phases within the low frequency data. The relatively conductive portion is also present as relatively high values around sites 03 and 04 within the phase pseudo-section.

We carried out sensitivity tests against three features in the resistivity distribution and determined that these features were sufficiently sensitive. One example (a test against C3) is shown in Figure 7. The sounding curves for both sites obtained from the modified model (green lines in Figure 7b) show significant deviations from the observed responses (red dots) at frequencies lower than $100 \mathrm{~Hz}$. This indicates that a relatively conductive zone (C3) is certainly present.

\section{Discussion}

\section{Origin of the shallow conductor}

As described in the previous section, a total of three features were identified in the resistivity distribution for the study area. A highly conductive region with resistivity values less than $10 \Omega \mathrm{m}$ extends beneath a significant part of the Jigokudani valley ( $\mathrm{C} 1$ and $\mathrm{C} 2$ in Figure 5); this nearsurface conductor is likely separated into upper and lower sections, with the former having a convex shape and is more conductive than the lower part.

The northeastern part of the Jigokudani valley contains laminated lacustrine sediments that are located at the base of an extinct crater lake (Kusakabe et al. 1983; 1986), whereas the southern area contains an active solfatara field, a hot water pool, and andesitic tuff breccias that are exposed on the hill side of the valley and has a valley side where these breccias are overlain by laminated lacustrine sediments (Kouno 1988). The distribution of solfataras in this area indicates that high-temperature volcanic gases are ascending beneath the southern area of the Jigokudani valley (Kouno 1988). The high temperature and acidic nature ( $\mathrm{pH}=1.7$ to 3.6; Mizutani et al. 2000) 

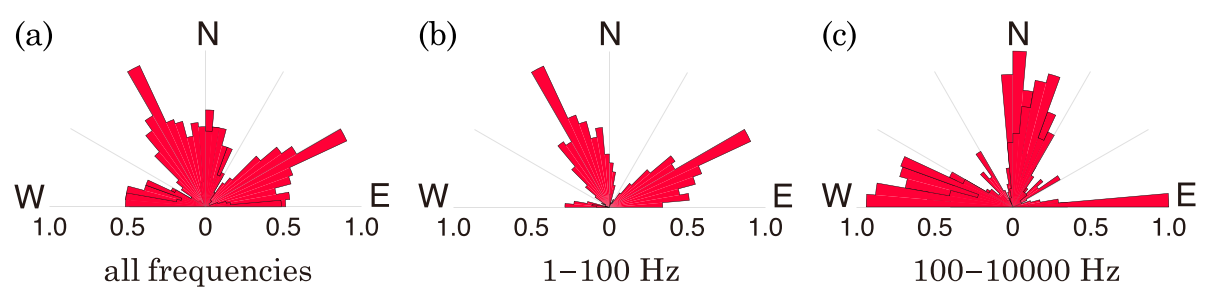

Figure 4 Polar histograms for phase-tensor ellipse principal axis directions at all sites. Histograms for (a) all frequency bands, (b) lower frequency bands (1 to $100 \mathrm{~Hz}$ ), and (c) higher frequency bands (100 to 10,000 Hz) are shown. Sector width is $5^{\circ}$, and the radial scale is normalized by the maximum value. Note that the directions have an intrinsic ambiguity of $90^{\circ}$ as discussed in the main text.

of these fluids has led to the development of hydrothermal kaolinite (Kusakabe et al. 1983). Although kaolinite itself possesses a higher resistivity, the presence of hot acidic fluids in areas with kaolinite can lead to a significant decrease in bulk resistivity (Takakura 2009). This indicates that the more conductive upper part $(\mathrm{C} 1)$ of the conductive body most likely represents clayey sediments containing acidic hydrothermal fluids (Figure 5).

The low permeable nature of clays means that these upper clayey sediments partly cap the upwelling volcanic gases and that the high-temperature gases in the lower part of the near-surface conductor (C2) appear slightly more resistive than the upper part of the conductor $(\mathrm{C} 1)$. The temperature of volcanic gases discharged from several fumaroles exceeds the boiling point of water in this area (Japan Meteorological Agency 2013b), which indicates the existence of the superheated vapor beneath the Jigokudani valley. The apparent equilibrium temperature of fumarolic gases estimated from the sulfur reaction suggests that the volcanic gases at shallow levels under the

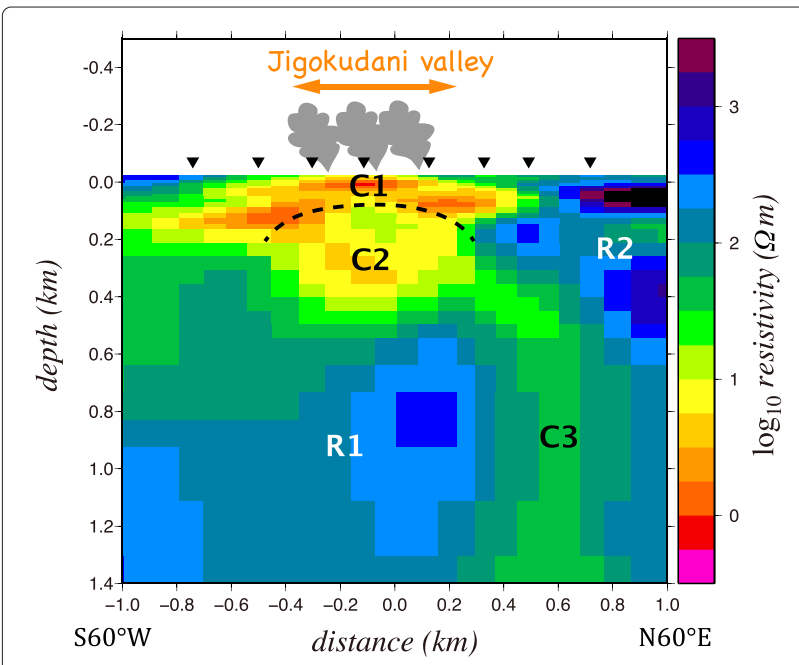

Figure 5 Final $2 \mathrm{D}$ resistivity model along the $560^{\circ} \mathrm{W}-\mathrm{N} 60^{\circ} \mathrm{E}$ line. Inverted triangles denote the AMT sites used for inversion, with three major fumarolic zones denoted by the cartoons of gray smoke.
Jigokudani valley are present at temperatures of $200^{\circ} \mathrm{C}$ to $340^{\circ} \mathrm{C}$ (Mizutani et al. 2000). The capping of these gases could cause an increase in pressure as the gases accumulate, creating the ideal setting for a phreatic explosion, although there are currently no geodetic data that would either support or disprove this hypothesis. However, it should be noted that the active fumaroles discharging superheated steam in the Jigokudani valley are located directly over the shallow conductor, as is seen in Figure 5.

\section{High resistivity layer and relatively conductive body}

Next, we consider the resistive layer present at depths below $500 \mathrm{~m}$ in the study area (R1 and R2 in Figure 5). These resistive zones are most likely composed of granitic basement material that is similar to the Tateyama volcanic edifice, which is dominated by granitic rocks. These granites and their metamorphosed equivalents are widespread throughout the Jigokudani valley (Harayama et al. 2000), including the granitic mountains to the northeast of the Jigokudani valley (Figure 1), that may be linked to the shallowing of the $\mathrm{R} 2$ resistive layer in this area.

This interpretation is supported from geochemical studies. The fumarolic gases within the Jigokudani valley have high ${ }^{3} \mathrm{He} /{ }^{4} \mathrm{He}$ ratios that are indicative of a dominantly magmatic origin (Nagao et al. 1981). Mizutani et al. (2000) reported that the magmatic gases contributed significantly to the fumarolic gases in this area and suggested that they were not contaminated by interaction with surface materials due to shallow basement rocks. These studies on fumarolic gases infer that the granitic basement is located at shallow levels, which is consistent with our interpretation of the high resistivity layer.

The relatively conductive body that extends subvertically from the shallow conductor is present within the deep resistive layer (C3 in Figure 5) and appears to separate the resistive granitic basement into two zones. Kobayashi and Hatano (1989) discussed the relationship between faulting and phreatic eruptions in the Jigokudani valley, which is located at the intersection of two faults. One of the two faults lies in a WSW-ENE direction from 


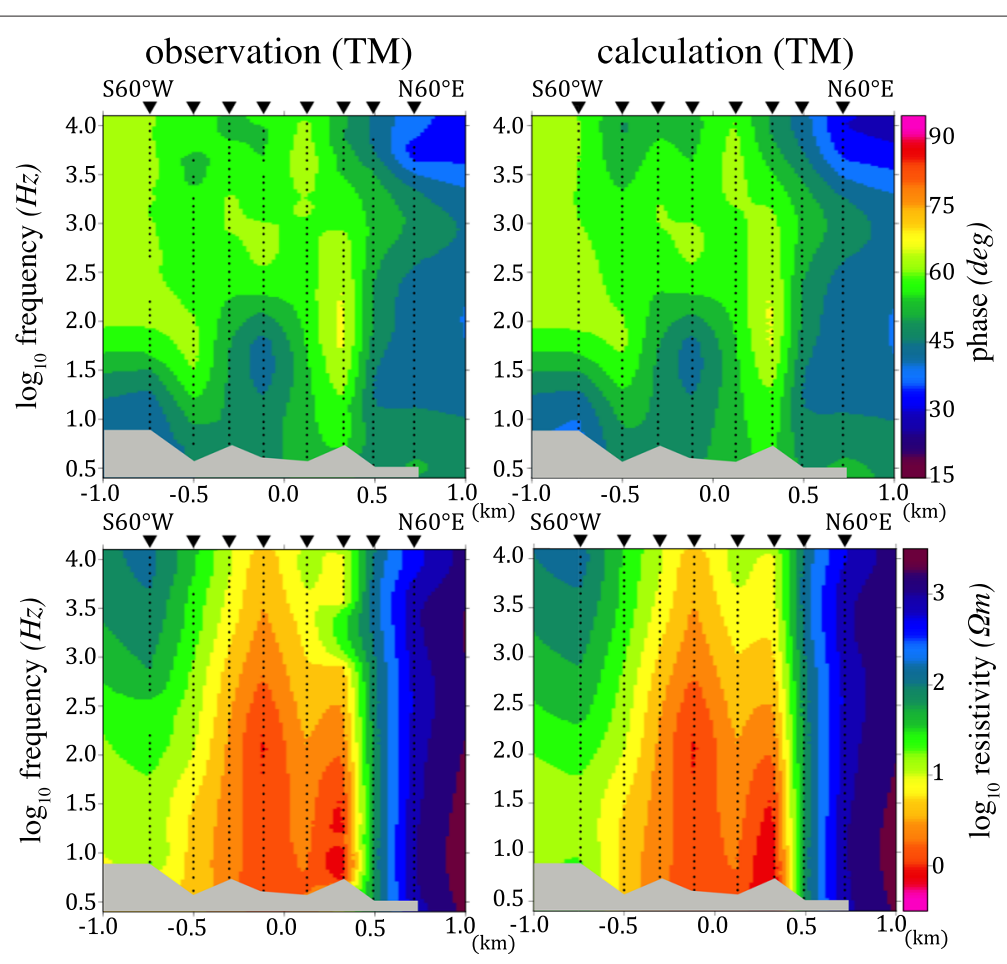

Figure 6 Comparison of pseudo-sections between the final 2D model responses (Figure 5) and the observed data. Left and right columns represent observed and calculated responses, respectively, with the upper chart showing TM-mode phase data and the lower chart showing TM-mode apparent resistivity data. Inverted triangles denote the AMT sites used for inversion (see Figure 1).

the Midagahara Plateau to the Jigokudani valley and has a length of approximately $7 \mathrm{~km}$. The other is a 9-km-long fault extending nearly south-southeastward from around the Jigokudani valley. These two faults are orthogonal to each other and form a conjugate fault system. The explosion craters within the Jigokudani valley define a NW-SE oriented trend (Figure 1), indicating that these faults and their associated eruptive activities were located along a NW-SE oriented principal compression axis in this area (Kobayashi and Hatano 1989). This model suggests that the area around the Jigokudani valley underwent NW-SEdirected compression that fractured the rocks in this area as a result of strain accumulation between faulting events. These fractures then led to interaction between nearsurface waters and heat sources, leading to numerous repeated phreatic eruptions within the Jigokudani valley (Kobayashi and Hatano 1989). This suggests that the relatively conductive body (C3) acts as a conduit for magmatic gases and most likely formed as a result of the fracturing outlined above. The heat source, and hence the source of the magmatic gases in this area, has been located at a depth of 2 to $4 \mathrm{~km}$ using seismic tomography (Matsubara et al. 2000), a depth that is greater than the investigation depth of the AMT study discussed here, indicating that longer period MT data would be required to detect this possible magma chamber.

\section{Conclusions}

Data obtained from an AMT survey undertaken along an ENE-WSW survey line that crossed the Jigokudani valley were used to determine the underground structure of an area underlying a zone of repeated phreatic eruptions. The $2 \mathrm{D}$ resistivity modeling undertaken during this study identified the following three features:

(1) A highly conductive region that extends to shallow levels beneath the Jigokudani valley. This conductor is divided into a conductive upper part and a less conductive lower part. The upper part most likely represents clayey sediments containing hydrothermal acid fluids, whereas the lower part is probably associated with the presence of rather resistive volcanic gases. The less permeable nature of the clay in this area means that the upper clayey sediments act as a cap that stores the magmatic gases in the lower part of this zone.

(2) A deep resistive layer that is present at depths below $500 \mathrm{~m}$ and is interpreted to represent granitic rocks that are widespread throughout the Jigokudani valley.

(3) A relatively conductive region that extends subvertically toward the shallow conductor and separates the deep resistive granitic layer into two sections. This zone most likely represents a conduit for magmatic gases, particularly since it underlies the most active fumarole in the Jigokudani valley. 
(a)

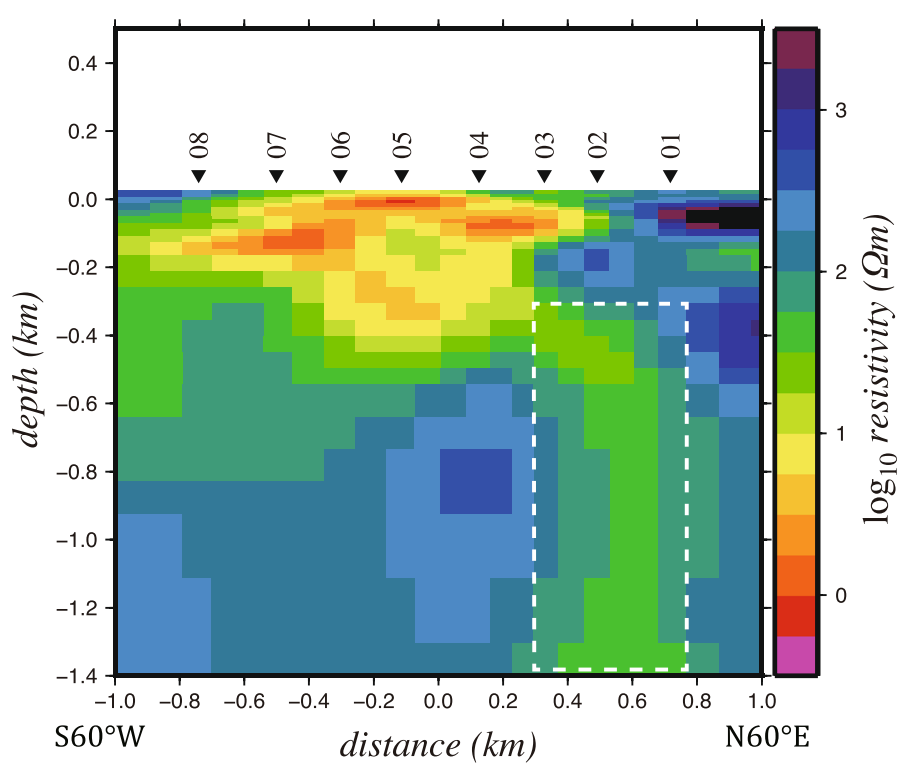

(b)

03
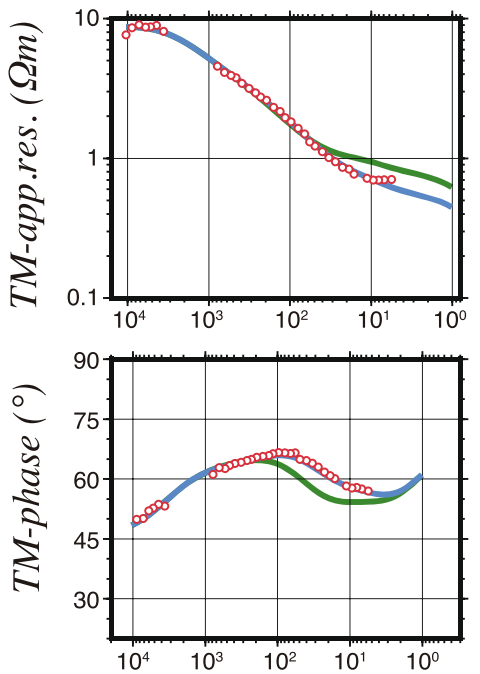

02
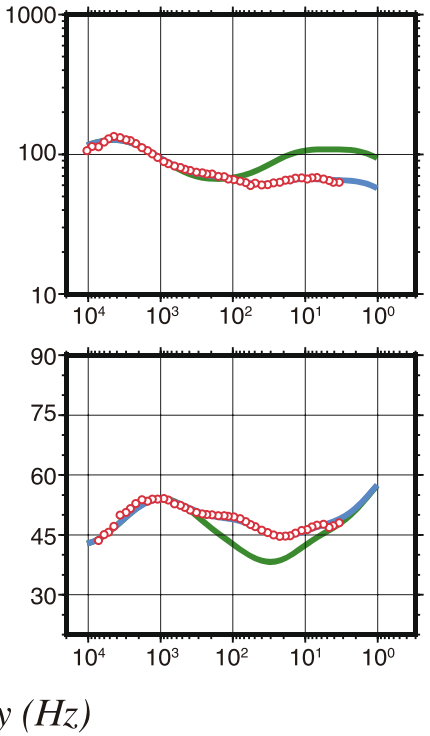

Figure 7 Results of the sensitivity test against a relatively conductive body (C3). (a) The resistivity of a region enclosed by the white dashed line was changed from the values of the best-fit model shown in the background to $200 \Omega \mathrm{m}$. (b) Sounding curves obtained from the modified model (green line) are shown together with observed responses (red dots) and the best-fit curves (blue line). TM-mode apparent resistivity (upper) and phase (lower) for sites 02 (right) and 03 (left) are shown.

The three features of the resistivity structure across the study area define a model where magmatic gases are supplied from a deep source to the Jigokudani valley, an area that has undergone numerous phreatic eruptions. Further research, including 3D modeling with denser AMT sites, is required to confirm this preliminary model.

\section{Competing interests}

The authors declare that they have no competing interests.

\section{Authors' contributions}

All authors participated in the acquisition of the data used during this study. KS analyzed the data, constructed the $2 \mathrm{D}$ resistivity model, and drafted the manuscript. WK conceived the study and revised the manuscript. All authors read and approved the final manuscript.

\section{Acknowledgements}

We are deeply grateful to the Tateyama Caldera Sabo Museum and the Tateyama Nature Conservation Center for their cooperation during our research. The Chubu Region Environmental Office, the Toyama District Forest Office, and Toyama Prefecture granted permission for the AMT survey 
undertaken within the Jigokudani valley during this study. We thank the staff at the Volcanic Fluid Research Center of Tokyo Institute of Technology for useful discussions. The constructive comments provided by the two anonymous referees and the Editor-in-Charge ( $\mathrm{H}$. Toh) were highly helpful to improve the manuscript. All of the figures used in this paper were prepared using Generic Mapping Tools (Wessel and Smith 1998). This study was supported by JSPS KAKENHI Grant Number 25350494.

\section{Author details \\ ${ }^{1}$ Department of Earth and Planetary Sciences, Tokyo Institute of Technology, 2-12-1 Ookayama, Meguro, Tokyo 152-8551, Japan. ${ }^{2}$ Volcanic Fluid Research Center, Tokyo Institute of Technology, 2-12-1 Ookayama, Meguro, Tokyo 152-8551, Japan. ${ }^{3}$ Tateyama Caldera Sabo Museum, Ashikuraji, Tateyama Toyama 930-1406, Japan. ${ }^{4}$ Geospatial Information Authority of Japan, Kitasato-1, Tsukuba, Ibaraki 305-0811, Japan. ${ }^{5}$ Current address: NS Solution Tokyo Corp., Shinkawa-2, Chuo, Tokyo 104-8280, Japan. ${ }^{6}$ Current address: Geothermal Energy Research \& Development Co., Ltd., Shinkawa-1, Chuo, Tokyo 104-0033, Japan.}

Received: 5 September 2014 Accepted: 9 December 2014

Published online: 15 January 2015

\section{References}

Aizawa K, Koyama T, Uyeshima M, Hase H, Hashimoto T, Kanda W, Yoshimura R, Utsugi M, Ogawa Y, Yamazaki K (2013) Magnetotelluric and temperature monitoring after the 2011 sub-Plinian eruptions of Shinmoe-dake volcano. Earth Planets Space 65:539-550. doi:10.5047/eps.2013.05.008

Barberi F, Bertagnini A, Landi P, Principe C (1992) A review on phreatic eruptions and their precursors. J Volcanol Geotherm Res 52:231-246. doi:10.1016/0377-0273(92)90046-G

Caldwell TG, Bibby HM, Brown C (2004) The magnetotelluric phase tensor. Geophys J Int 158:457-469. doi:10.1111/j.1365-246X.2004.02281.x

Germanovich LN, Lowell RP (1995) The mechanism of phreatic eruptions. J Geophys Res 100:8417-8434. doi:10.1029/94JB03096

Harayama S, Takahashi Y, Nakano S, Kariya Y, Komazawa M (2000). Geology of the Tateyama district, with Geological Sheet Map at 1:50,000. Geol Surv Japan, Tsukuba [in Japanese with English abstract]

Japan Meteorological Agency (2013a) Midagahara. In: Japan Meteorological Agency, The Volcanological Society of Japan (eds) National catalogue of the active volcanoes in Japan, (4th edition). Japan Meteorological Agency, Tokyo

Japan Meteorological Agency (2013b) Midagahara, Data presented at the National Committee for Prediction of Volcanic Eruption No.125 on Mar.12. http://www.data.jma.go.jp/svd/vois/data/tokyo/STOCK/kaisetsu/CCPVE/ shiryo/125/125_no05_2.pdf Accessed 6 Jan 2015 [in Japanese]

Kobayashi T (1980) The recent deposits of phreatic explosions in Tateyama volcano. Bull Volcanol Soc Jpn 25(4):297. [in Japanese]

Kobayashi T, Hatano S (1989) Genetic relation between phreatic explosions of the 4th volcanic period and fault movements of Midagahara Fault on Tateyama volcano, central Honshu. Bull Volcanol Soc Jpn 34(4):348. [in Japanese]

Kouno T (1988) 'Hoguchi' sulfur from the Jigokudani valley, Tateyama volcano. Geol Rept Shimane Univ 7:91-97. [in Japanese]

Kusakabe M, Hayashi N, Kobayashi T (1983) Genesis of banded sulfur sediments at the Jigokudani valley, Tateyama volcano, Japan. Bull Volcanol Soc Jpn 28:245-261. [in Japanese with English abstract]

Kusakabe, M, Hayashi N, Kobayashi T (1986) Genetic environments of the banded sulfur sediments at the Tateyama Volcano, Japan. J Geophys Res 91:12159-12166. doi:10.1029/JB091iB12p12159

Matsubara M, Hirata N, Sakai S, Kawasaki I (2000) A low velocity zone beneath the Hida Mountains derived from dense array observation and tomographic method. Earth Planets Space 52:143-154. doi:10.1186/BF03351623

Mizutani Y, Sasaki Y, Hori M, Koyama M (2000) Chemical compositions and isotopic ratios of fumarolic gases and hot spring waters from Tateyama-jigokudani, Toyama, Japan. Chikyukagaku (Geochemistry) 34:77-89. [in Japanese with English abstract]

Nagao K, Takaoka N, Matsubayashi O (1981) Rare gas isotopic compositions in natural gases of Japan. Earth Planet Sci Lett 53:175-188. doi:10.1016/0012-821X(81)90152-7
Nakano S, Itoh J (1998) Eruption records of Tateyama volcano. Bull Volcanol Soc Jpn 43:123-126. [in Japanese]

Nurhasan, Ogawa Y, Ujihara N, Tank SB, Honkura Y, Onizawa Y, Mori T, Makino M (2006) Two electrical conductors beneath Kusatsu-Shirane volcano, Japan, imaged by audiomagnetotellurics, and their implications for the hydrothermal system. Earth Planets Space 58:1053-1059. doi:10.1186/BF03352610

Ogawa Y, Uchida T (1996) A two-dimensional magnetotelluric inversion assuming Gaussian static shift. Geophys J Int 126:69-76. doi:10.1111/j.1365-246X.1996.tb05267.x

Ogawa Y, Takakura S, Honkura Y (2002) Resistivity structure across Itoigawa-Shizuoka tectonic line and its implications for concentrated deformation. Earth Planets Space 54:1115-1120. doi:10.1186/BF03353311

Ohba T, Kitade Y (2005) Subvolcanic hydrothermal systems: implications from hydrothermal minerals in hydrovolcanic ash. J Volcanol Geotherm Res 145:249-262. doi:10.1016/j.jvolgeores.2005.02.002

Parkinson WD (1962) The influence of continents and oceans on geomagnetic variations. Geophys J Int 6:441-449. doi:10.1111/j.1365-246X.1962.tb02992.x

Pellerin L, Johnston JM, Hohmann GW (1996) A numerical evaluation of electromagnetic methods in geothermal exploration. Geophysics 61:121-130. doi: 10.1190/1.1443931

Takakura S (2009) Influence of pore-water salinity and temperature on resistivity of clay-bearing rocks. Soc Explor Geophys Jpn 62:385-396. [in Japanese with English abstract]

Tokyo Institute of Technology, Geo-heat Promotion Association of Japan, Asia Air Survey Co. Ltd (2013) Midagahara, Data presented at the National Committee for Prediction of Volcanic Eruption No.127 on Oct.22. http:// www.data.jma.go.jp/svd/vois/data/tokyo/STOCK/kaisetsu/CCPVE/shiryo/ 127/127_no05_1.pdf Accessed 6 Jan 2015 [in Japanese]

Ussher G, Harvey C, Johnstone R, Anderson E (2000) Understanding the resistivities observed in geothermal systems. Proc World Geotherm Congr, Kyusyu-Tohoku, Japan. 1915-1920

Wessel P, Smith WHF (1998) New, improved version of Generic Mapping Tools released. EOS Trans Am Geophys U 79:579

Wright PM, Ward SH, Ross HP, West RC (1985) State-of-the-art geophysical exploration for geothermal resources. Geophysics 50:2666-2699. doi:10.1190/1.1441889

Yamasaki M, Nakanishi N, Miyata K (1966) History of Tateyama Volcano. Sci Rep Kanazawa Univ 11(01):73-92

Yamaya Y, Alanis PKB, Takeuchi A, Cordon JM, Mogi T, Hashimoto T, Sasai Y, Nagao T (2013) A large hydrothermal reservoir beneath Taal Volcano (Philippines) revealed by magnetotelluric resistivity survey: 2D resistivity modeling. Bull Volcanol 75:729. doi:10.1007/s00445-013-0729-y

\section{Submit your manuscript to a SpringerOpen ${ }^{\circ}$ journal and benefit from:}

- Convenient online submission

Rigorous peer review

- Immediate publication on acceptance

- Open access: articles freely available online

- High visibility within the field

- Retaining the copyright to your article

Submit your next manuscript at $>$ springeropen.com 